\section{Use of Ammonium Hexanitrato Cerate(IV) for the Oxidimetric Determination of Ethylene Glycol, Glycerol, Mannitol and Sorbitol}

Verwendung von Ammoniumhexanitratocerat(IV) zur oxidimetrischen Bestimmung von Äthylenglykol, Glycerin, Mannit und Sorbit

\section{B. Madhaya Rao and G. Gopala Rao}

Department of Chemistry, Andhra University, Waltair, India

Received November 1, 1971

Ammonium hexanitrato cerate(IV) has already been employed by Gopala Rao, Krishna Rao, and Murthy $[1,2]$ for the oxidimetric titration of oxalic and mandelic acids. This reagent has several advantages over cerium $(\mathrm{IV})$ perchlorate or sulphate, as it can be prepared in a high state of purity, can be stored for a long time in amber coloured bottles and is also commercially available. It has now been applied to the oxidimetric titration of several polyhydric alcohols, i.e., ethylene glycol, glycerol, mannitol and sorbitol. These alcohols are oxidised quantitatively to formic acid under the conditions involved in the procedure given below. The errors of the determinations are within $\pm 1 \%$.

Procedure. Mix an aliquot of the sample $(20-60 \mathrm{mg}$ of ethylene glycol, $12-42 \mathrm{mg}$ of glycerol, $35-65 \mathrm{mg}$ of mannitol or sorbitol) with a 1.5 to 2.0 times excess of reagent solution in $1 \mathrm{~N}$ nitric acid as required for complete oxidation and dilute to an overall acidity of $0.5 \mathrm{~N}$. Heat on a water bath to $50-60^{\circ} \mathrm{C}$ for $45 \mathrm{~min}$ (in the case of ethylene glycol and glycerol) or for $75 \mathrm{~min}$ (in the case of mannitol and sorbitol), cool, treat with $10 \mathrm{ml}$ of $1 \mathrm{~N}$ sulphuric acid and back-titrate with a standard solution of iron(II) to a ferroin end-point.

This method is preferable to the one using periodate in view of the more favourable stoichiometry.

Acknowledgement. One of the authors (B.M.R.) is thankful to the Principal, S.F.S. College, Nagpur, Fr.P. Falleiro, for granting have during the progress of this work.

\section{References}

1. Rao, G. Gopala, Rao, P. V. Krishna, Murthy, K. S.: Talanta 9, 835 (1962); cf. Z. Anal. Chem. 201, 459 (1964).

2. - Murthy, K. S., Rao, P. V. Krishna: Talanta 10, 657 (1963); cf. Z. Anal. Chem. 207, 44 (1965).

Prof. Dr. G. Gopala Rao

Department of Chemistry, Andhra University Waltair, India 